\title{
Uncertainty in Dispersion Forecasting using Meteorological Ensembles
}

\author{
M. J. Leach, H. -N. Chin
}

This article was submitted to Millennium NATO/CCMS International Technical Meeting on Air Pollution Modeling and Its Application

Boulder, $\mathrm{CO}$

May $15-19,2000$

\section{March 23, 2000}




\section{DISCLAIMER}

This document was prepared as an account of work sponsored by an agency of the United States Government. Neither the United States Government nor the University of California nor any of their employees, makes any warranty, express or implied, or assumes any legal liability or responsibility for the accuracy, completeness, or usefulness of any information, apparatus, product, or process disclosed, or represents that its use would not infringe privately owned rights. Reference herein to any specific commercial product, process, or service by trade name, trademark, manufacturer, or otherwise, does not necessarily constitute or imply its endorsement, recommendation, or favoring by the United States Government or the University of California. The views and opinions of authors expressed herein do not necessarily state or reflect those of the United States Government or the University of California, and shall not be used for advertising or product endorsement purposes.

This is a preprint of a paper intended for publication in a journal or proceedings. Since changes may be made before publication, this preprint is made available with the understanding that it will not be cited or reproduced without the permission of the author.

This report has been reproduced directly from the best available copy.

Available electronically at http://www.doc.gov/bridge

Available for a processing fee to U.S. Department of Energy

And its contractors in paper from

U.S. Department of Energy

Office of Scientific and Technical Information

P.O. Box 62

Oak Ridge, TN 37831-0062

Telephone: (865) 576-8401

Facsimile: (865) 576-5728

E-mail: reports@adonis.osti.gov

Available for the sale to the public from

U.S. Department of Commerce

National Technical Information Service

5285 Port Royal Road

Springfield, VA 22161

Telephone: (800) 553-6847

Facsimile: (703) 605-6900

E-mail: orders@ntis.fedworld.gov

Online ordering: http:/ / www.ntis.gov/ordering.htm

\section{OR}

Lawrence Livermore National Laboratory

Technical Information Department's Digital Library

http: / / www.llnl.gov/tid/Library.html 


\section{Uncertainty in dispersion forecasting using meteorological ensembles Martin J. Leach and H.-N. Chin Atmospheric Science Division Lawrence Livermore National Laboratory Livermore CA 94550}

\section{Introduction}

An approach for quantifying meteorological uncertainty is via development of an ensemble of forecasts from slightly perturbed initial conditions (Sivillo et al., 1997) to predict the time evolution of the probability density function of atmospheric variables (Mullen and Baumhefner, 1994). We create an ensemble of forecasts by varying the initial (and boundary) conditions for the COAMPS meteorological model. The variations in the initial conditions must be consistent with analysis error. Optimally, the range of initial conditions would encompass the "true" atmospheric state, but which is never actually known. Our method for creating varying initial conditions is to use different global data sets to derive the necessary data. We use two models from the National Weather Service (the AVN and ETA models) and one from the Navy (the NOGAPS model). In addition to those data sets we perturb the data from those models, using a normally distributed random number at each grid point in the COAMPS model. We perturb the $(\mathrm{u}, \mathrm{v})$ wind components, the temperature and the moisture. The size of the perturbation is determined by the variability within that variable field. The forecasts are run for 48 hours. We then use the output from the COAMPS model to drive a Lagrangian dispersion model (LODI) for simulated releases. The results from a simulated release from hour 33 are shown in Figure 1. The center of the domain is Oakland airport and the basic on-shore wind is from the southwest. In three of the simulations, the plume goes over the top of the hills to the northeast, and in the other three the plume hugs the coastline and goes around those hills The two solutions reflect a dependence on the Froude number, a ratio of the Kinetic energy to Potential energy. Higher Kinetic energy flow (Higher Froude number) flow goes over the top of the mountain, while lower Kinetic energy flow goes around the hills.

\section{Model Descriptions}

A. COAMPS (The Coupled Ocean/Atmosphere Mesoscale Prediction System) The Coupled Atmosphere/Ocean Mesoscale Prediction System (COAMPS) model (Hodur, 1997) was developed at the Naval Research Laboratory. COAMPS has been used at resolutions as small as $2 \mathrm{~km}$ to study the role of complex topography in generating mesoscale circulation (Doyle, 1997). The model has been adapted for use in the Atmospheric Science Division at LLNL for both research and operational use. The model is a fully explicit, non-hydrostatic model with several options for turbulence parameterization, cloud processes and radiative transfer. We have recently modified the code to include an urban canopy parameterization (Brown and Williams, 1998), based on Yamada's (1982) forest canopy parameterization and includes modification of the the and mean momentum equations, modification of radiative transfer, and an anthropogenic heat

This work was performed under the auspices of the U.S. Department of Energy by the University of California, Lawrence Livermore National Laboratory under Contract No. W-7405-Eng-48. 
source. COAMPS is parallelized for both shared memory (OpenMP) and distributed memory (MPI) architecture.

A. LODI (Livermore Operational Dispersion Integrator. A Lagrangian Particle Model) The dispersion model, LODI, (Nasstrom et al.,2000) simulates the processes of advection, turbulent diffusion, radioactive decay and first order chemical reaction, wet and dry deposition and plume rise. The model uses a Lagrangian, stochastic Monte Carlo method, and is capable of simulations with complex terrain Similarly to COAMPS, the model is parallelized for both shared memory and distributed memory architecture.

\section{Experimental Design}

COAMPS is a regional atmospheric model, requiring initial conditions and boundary conditions from larger-scale models. To create a forecast ensemble, we derived the initial and boundary conditions from 3 models, the Navy's global NOGAPS model, the National Weather Service's (NWS) global Aviation model and the NWS regional Eta model. Using the 3 models, we performed three, 48 hour forecasts using COAMPS. We increased the size of our ensemble by adding small random perturbations to the initial and boundary conditions from the large scale model. Perturbations were only added to the horizontal velocity components $(\mathrm{u}, \mathrm{v})$ and to the temperature. All other variables were unperturbed. The size of the random perturbation was determined by the variance in the field itself. The COAMPS forecast used two grids, one nested within the other. Oakland airport is the center of the domain in both nests, and is also the release point for the simulated tracer.

\section{Forecast Dispersion Pattern}

Wind forecasts from the COAMPS meteorological model are used to drive the LODI dispersion model. The Results of a three-hour dispersion model simulation, from hour 33 to hour 36 from the COAMPS forecast, are shown in Figure 1. The initial time of the forecast is August 23 at 0000 UTC (August 22, 1700 local time). There is a very distinctive bifurcation in the solutions; three of the plumes travel towards the northeast over the hills, while three of the plumes travel northwest, staying over the bay and hugging the coastal hills. In general the plumes that go over the hills are narrower, while those that go along the shoreline are wider. This indicates stronger winds for the plumes going over the hills. The exception is for the AVN model without perturbation. 


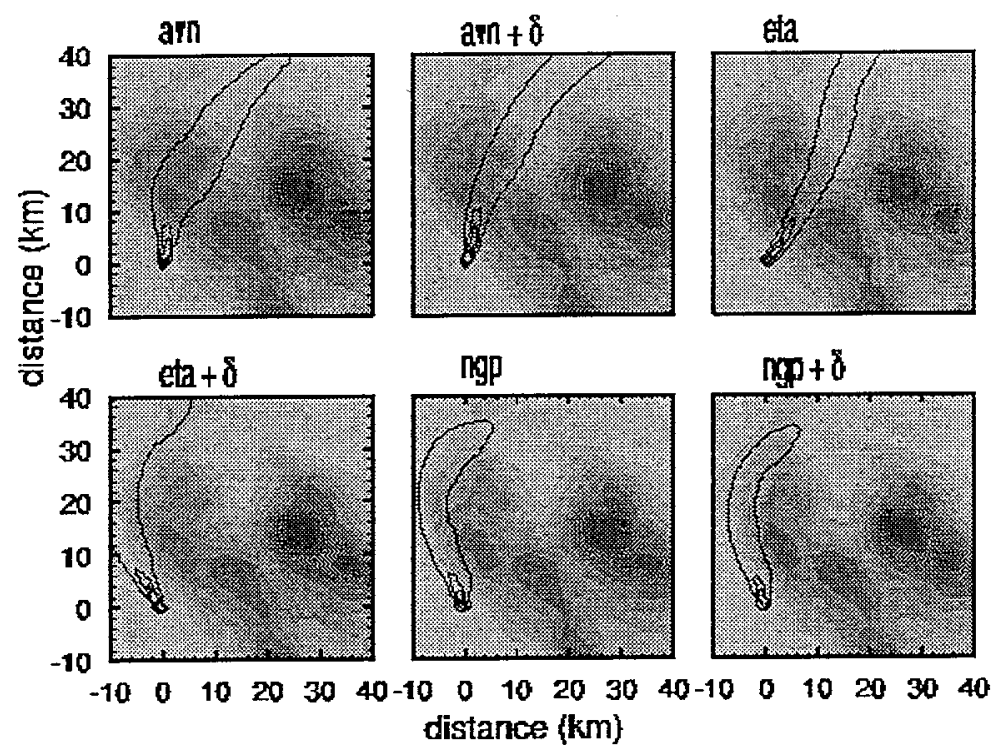

Figure 1. The dispersion patterns for three hour predictions from hour 33 to hour 36 . The runs are labeled with the large scale model used to generate initial conditions, including the runs with the random perturbation imposed $(+\delta)$.

\section{Forecast Wind Field}

Representative wind fields that drive the forecasts are shown in Figure 2. These winds are from hour 36 in the forecast, valid at 1200 UTC on August 25, or 0500 local time and are from the fourth level from the ground in the COAMPS model, approximately 140 meters above the surface. Qualitatively, all of the forecasts look similar, an indication that the forecasts have not diverged significantly to this point in the simulations. There is strong westerly flow in the western portion of the domain that turns cyclonically towards the north (southerly winds) near the center of the upper-half of the domain. On closer inspection of the wind fields however, it is apparent that in the three cases where the plume goes over the top of the hills, the wind shift to southerly winds is farther to the east than in the three cases where the plume stays along the shoreline. Stronger flow in the southern portion of the domain is apparent in the three cases where the flow traverses over the hills. An anti-cyclonic turn of the winds to westerly flow in the northeast section of the domain that is more pronounced in the three cases where the plumes did not traverse the hills but stayed along the shoreline. 


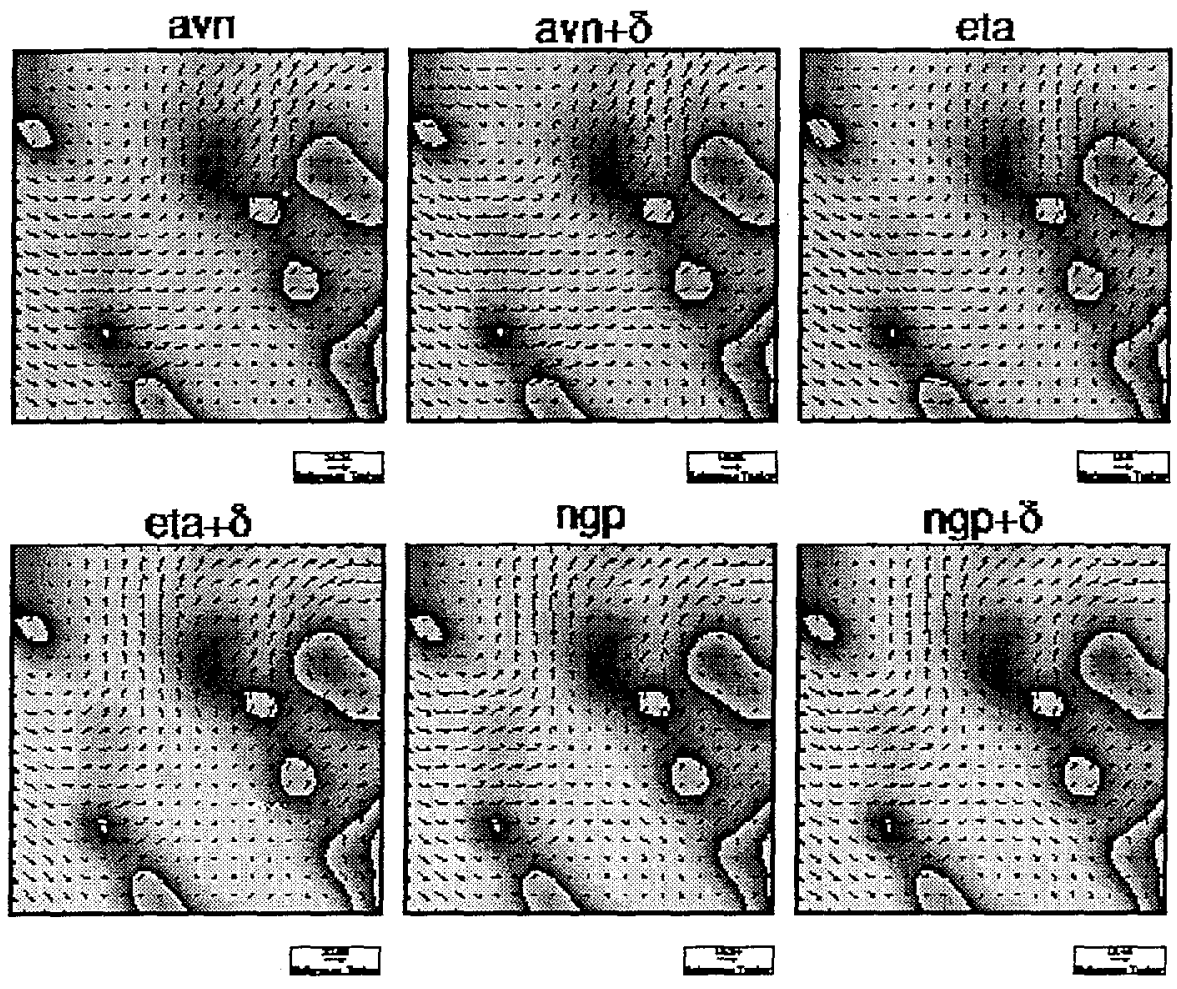

Figure 2. The wind fields for the six forecasts, labeling of the forecasts as in Figure 1,

\section{Froude Number}

The mesoscale influence of underlying terrain is evident in the simulations in a way that also shows the uncertainty of the meteorological forecasts. The influence is felt through a blocking effect. As air starts to move up the side of a hill, the air loses kinetic energy and gains potential energy. If the air gets to the top of the hill, before losing all of its kinetic energy, then it moves across the top of the hill. Conversely, if the air loses all of its kinetic energy before it reaches the hilltop, then it will not go over the hill, but rather will move around it, tuning cyclonically (towards lower pressure). The well-known Froude number is a measure of this effect. The meteorological definition of the Froude number is

$$
\mathrm{Fr}=\mathrm{U} / \mathrm{Nh}
$$

Where Fr is the Froude number, $\mathrm{U}$ is the wind speed, $\mathrm{N}$ is the Brunt-Vaisala frequency, a measure of atmospheric stability and $h$ is the height of the blocking hill. The meteorological Froude number includes the atmospheric stability effect through $\mathrm{N}$. Higher values of $\mathrm{N}$ reflect greater atmospheric stratification and therefore more stable air would require greater wind speeds to go over the top of the hill. Table I contains the relevant values for the six cases illustrated in the figures above. The numbers in the tables 
were calculated using 9 grid points $(3 \times 3)$ centered on the hill. The wind speed and stability were calculated using the lowest 6 levels from the COAMPS model, which is approximately the lowest 330 meters above ground level. It is clear from the values in the table that the Froude number accurately diagnosis whether the air and therefore the plume, goes over the hills or goes around. In the three cases going over the hill, the Froude number is greater the 1 , indicating higher wind speeds, or lower stability. When the Froude number is less than 1 , the plume did not go over the hill, but stayed along the shoreline.

\begin{tabular}{|l|l|l|l|}
\hline Forecast & Froude Number & U & N \\
\hline AVN & 1.63 & 16.8 & 0.031 \\
\hline AVN $+\delta$ & 2.06 & 21.5 & 0.032 \\
\hline ETA & 3.17 & 24.7 & 0.024 \\
\hline ETA $+\delta$ & 0.98 & 11.7 & 0.036 \\
\hline NGP & 0.67 & 9.0 & 0.040 \\
\hline NGP $+\delta$ & 0.67 & 8.6 & 0.039 \\
\hline
\end{tabular}

Table I. The Froude number, mean wind velocity $(U)$ in the lowest 330 meters and the Brunt-Vaisala $(N)$ frequency for the six forecasts.

One-hour LODI simulations were produced from every 12 hours throughout the 48-hour COAMPS forecast. The results are plotted in

\section{AVN}
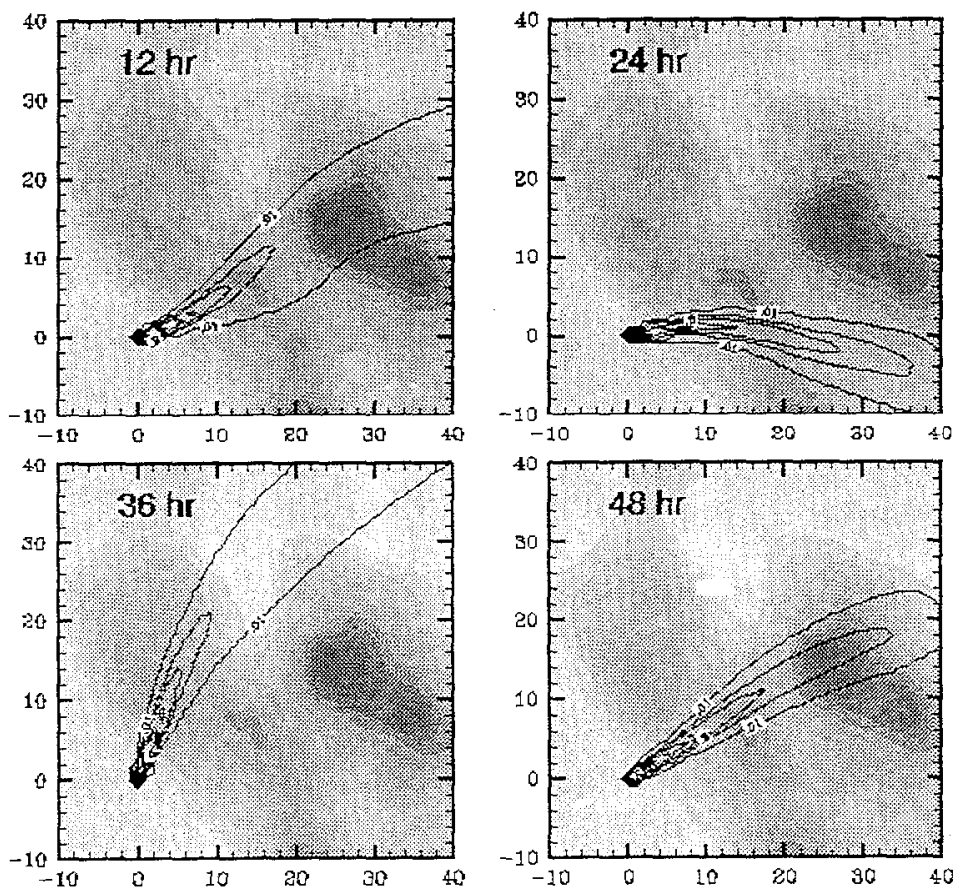

gure 3, for the COAMPS runs

Figure 3.Dispersion patterns using winds from COAMPS forecasts, with the Aviation model as the large scale forcing. The underlying terrain is represented in gray-scale. 
using AVN as for the initial and boundary conditions. It is clear that diurnal forcing exists. A similar diurnal feature exists in all runs (not shown). A strong onshore wind, consistent with a sea-breeze, exists for the afternoon 24 hour and 48 hour forecasts in all cases. This case was a very warm day in August with temperatures in the Livermore Valley and Central Valley exceeding $100 \mathrm{~F}$. At night, the sea-breeze circulation relaxes, synoptic forcing dominates and more southerly winds are most normal. At all hours in the forecast, it appears that the more than one solution exists and is dependent on terrain forcing. As early as 12 hours, differences in the plume forecasts are evident, with the bifurcation that is detailed in the 36 hours forecasts already apparent. Daytime plumes tend to ride westerly winds, but which gap in the terrain that they traverse depends on the forecast. For instance at 24 hours, the NGP and AVN runs are very similar, by 48 hours they are very different with the NGP run much farther to the south. The ETA model run maintains the strongest circulation and synoptic forcing. It is least affected by the terrain induced local forcing and hence variability in the plume forecasts is much less.

\section{Probability}

The probability that the concentration will exceed 0.01 of the maximum concentration amount (Figure 4) demonstrates the uncertainty within the forecasts and that the uncertainty is not simply sub-grid scale due to turbulence fluctuations. It is clear from the 12 hour and 48 hour forecasts, that two solutions are possible, at least from this limited ensemble. Similarly it appears that three solutions are possible from the 24 hour forecasts. Local forcing, interacting with the synoptic (large-scale) forcing is responsible for the uncertainty. Small changes in the synoptic conditions lead to rather large changes in the small scale solutions. 
Probability
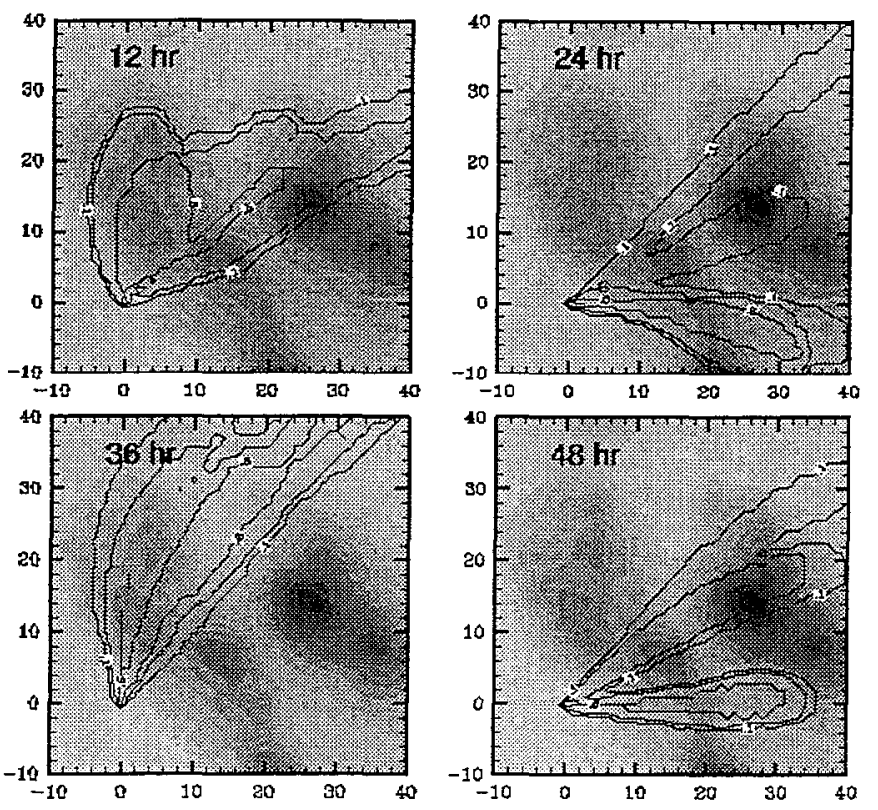

Figure 4 . The probability contours of exceeding 0.01 of maximum concentration value at the four times. 